\title{
CONDUTÂNCIA ESTOMÁTICA EM FOLHAS DE FEIJOEIRO SUBMETIDO A DIFERENTES REGIMES DE IRRIGAÇÃ̃ ${ }^{1}$
}

\author{
AURICLEIA S. PAIVA ${ }^{2}$, EDEMO J. FERNANDES ${ }^{3}$, TERESINHA J. D. RODRIGUES ${ }^{4}$, \\ JOSÉ E. P. TURCO ${ }^{3}$
}

RESUMO: O controle estomático é importante propriedade fisiológica por meio da qual as plantas limitam a perda de água, ocasionando reduções na condutância estomática e, geralmente, reduzindo as trocas gasosas como forma de resposta das plantas a diversos fatores, incluindo o estresse hídrico. $\mathrm{O}$ objetivo deste trabalho foi determinar a condutância estomática em folhas de feijoeiro submetido a diferentes regimes de irrigação. O experimento foi conduzido no Departamento de Engenharia Rural da Faculdade de Ciências Agrárias e Veterinárias de Jaboticabal - SP. As irrigações nos tratamentos foram determinadas em função do esgotamento de água no solo: T1 - irrigado quando esse atingiu $40 \%$ da capacidade de água disponível (CAD); T2 - quando atingiu 60\% da CAD; T3 - quando atingiu $80 \%$ da CAD, e T4 - não irrigado (irrigado somente para favorecer a emergência das plântulas). As medições de condutância estomática foram realizadas diariamente no campo, nas duas faces da folha, utilizando-se de um porômetro. Em todos os tratamentos, em diversas medições, foi observada redução da condutância estomática em resposta a baixos valores de potencial mátrico e a altos valores de déficit de pressão de vapor e vice-versa. As folhas das plantas do tratamento T4, que foram submetidas a menor disponibilidade hídrica no solo, apresentaram os menores valores de condutância estomática durante os estádios do florescimento e enchimento de grãos.

PALAVRAS-CHAVE: estresse hídrico, água no solo, Phaseolus vulgaris L.

\section{STOMATAL CONDUCTANCE IN LEAVES OF BEAN PLANTS SUBMITTED TO DIFFERENT IRRIGATION REGIMES}

\begin{abstract}
Stomatal control is an important physiological process for plants to reduce water loss. It causes reduction in stomatal conductance and generally in gas exchanges, as a response of several factors including water stress. The objective of this study was to determine the stomatal conductance of bean leaves submitted to different irrigation regimes. Field experiment was conducted at the São Paulo State University, in Jaboticabal, Brazil. Irrigation of the treatments occurred when available water capacity in the soil decreased to 40; 60 and $80 \%$ (respectively, treatments T1, T2 and T3), while irrigation in T4 occurred only to assure seedling emergence. Direct measurements of stomatal conductance were taken every day under field conditions in both adaxial and abaxial leaf surfaces using porometer. In all treatments, several measurements showed reduced stomatal conductance in response to low values of matric potential and high values of vapor pressure deficit (DPV) and viceversa. The lowest values of stomatal conductance of T4 leaves, taken from plants under the most restrictive water supply regime tested in this study, were observed during the period of plant flowering and grain development.
\end{abstract}

KEYWORDS: water stress, soil water, Phaseolus vulgaris L.

\footnotetext{
${ }^{1}$ Extraído da dissertação de Mestrado da primeira autora.

${ }^{2}$ Eng ${ }^{\text {a }}$ Agr ${ }^{\text {a }}$., Especialista em Irrigação e Drenagem, Mestre em Ciência do Solo, clepaiva@ fcav.unesp.br

${ }^{3}$ Prof. Adjunto, Departamento de Engenharia Rural, UNESP, Jaboticabal - SP.

${ }^{4}$ Prof. Adjunto, Departamento de Biologia Aplicada à Agropecuária, UNESP, Jaboticabal - SP. Bolsista do CNPq.

Recebido pelo Conselho Editorial em: 30-9-2003

Aprovado pelo Conselho Editorial em: 28-4-2005
} 


\section{INTRODUÇÃO}

A produção agrícola é dependente de vários fatores, tais como água, nutrientes e luz, sendo a água o fator mais limitante para a sustentabilidade dos sistemas agrícolas. Considerando-se que $70 \%$ da água utilizada no mundo se destina à irrigação, é relevante o uso racional desse recurso pelo fornecimento adequado às culturas. Para manejar adequadamente sistemas irrigados, é de fundamental importância a definição do momento de irrigação e da quantidade adequada de água às culturas. Para isso, torna-se necessário o conhecimento das necessidades hídricas das plantas, bem como a fase de maior exigência de água das mesmas, sendo tal informação indispensável para o êxito do empreendimento.

As plantas, ao absorverem $\mathrm{CO}_{2}$, inevitavelmente, perdem água pelas folhas. Essa perda de água ocorre principalmente através dos estômatos, que apresentam mecanismos para controlar o seu grau de abertura. Esse controle é atribuído à condutância estomática foliar, que é freqüentemente utilizada como indicador da deficiência hídrica (Mc DERMIT, 1990).

O decréscimo na disponibilidade de água no solo ocasiona queda no potencial da água nas folhas das plantas, levando à perda de turgescência e à redução da condutância estomática (SHALHEVET, 1983). A redução da taxa de assimilação de $\mathrm{CO}_{2}$ durante o estresse hídrico deve-se à redução na disponibilidade de $\mathrm{CO}_{2}$ no interior da folha, causada pelo fechamento dos estômatos em resposta à redução da disponibilidade de água no solo (ROSA et al., 1991). Esse aumento da resistência à difusão gasosa e a diminuição na taxa de assimilação de $\mathrm{CO}_{2}$ determina menor perda de água por transpiração, além de poder afetar a fotossíntese.

De acordo com GHOLZ et al. (1990), a disponibilidade de água afeta o crescimento das plantas, por controlar a abertura dos estômatos e, conseqüentemente, a produção de fitomassa. $\mathrm{O}$ decréscimo de água no solo diminui o potencial de água na folha e sua condutância estomática, promovendo o fechamento dos estômatos. Esse fechamento bloqueia o fluxo de $\mathrm{CO}_{2}$ para as folhas, afetando o acúmulo de fotoassimilados, o que pode reduzir a produtividade.

O conhecimento das respostas de alguns atributos fisiológicos às variações da disponibilidade hídrica no solo, principalmente nos estádios de maior exigência hídrica da cultura, é de grande importância no uso e manejo da irrigação, visando à maximização da produção e maior economia no uso da água. Em função disso, teve-se o objetivo de determinar a condutância estomática em folhas de feijoeiro submetido a diferentes regimes de irrigação.

\section{MATERIAL E MÉTODOS}

O experimento foi instalado na Área Demonstrativa e Experimental de Irrigação (ADEI), da UNESP, Jaboticabal - SP. As coordenadas geográficas são $21^{\circ} 14^{\prime} 48^{\prime \prime}$ de latitude sul e $48^{\circ} 16^{\prime} 44^{\prime \prime}$ de longitude oeste, sendo a altitude média de $557 \mathrm{~m}$.

O solo da área experimental foi classificado como Latossolo Roxo por ALOISI \& DEMATTE (1974) ou Latossolo Vermelho (eutroférrico típico) por ANDRIOLI \& CENTURION (1999), de acordo com as recomendações de classificação de solos da EMBRAPA (1999). O preparo do solo da área experimental constou de uma aração e duas gradagens. A adubação da cultura foi efetuada de acordo com recomendação baseada na análise do solo, efetuando-se uma adubação de semeadura de $15 \mathrm{~g} \mathrm{~m}^{-1} \mathrm{com}$ a formulação 4-20-20 (NPK) e, 30 dias após a semeadura, uma adubação de cobertura com sulfato de amônio, utilizando-se da $150 \mathrm{~kg} \mathrm{ha}^{-1}$.

Utilizou-se de sistema de irrigação por aspersão convencional, sendo instalada na área experimental a cultura do feijão (Phaseolus vulgaris L.), cultivar carioca 80, com hábito de crescimento indeterminado e ciclo de 90 dias. 
O experimento foi instalado no dia 24 de abril de 2002, utilizando-se de 21 sementes por metro quadrado e quatro tratamentos em área total de 1,0 ha, sendo 0,2 ha a área útil de cada parcela.

Os métodos utilizados para a irrigação de cada tratamento foram função do esgotamento de água no solo: T1 - irrigado quando esse atingiu $40 \%$ da capacidade de água disponível (CAD) (ALLEN et al., 1998); T2 - irrigado quando o esgotamento de água no solo atingiu 60\% da CAD; T3 - irrigado quando o esgotamento de água no solo atingiu $80 \%$ da CAD, e T4 - irrigado somente para favorecer a emergência das plântulas.

A capacidade de água disponível no solo foi determinada considerando a profundidade efetiva do sistema radicular de 0,40 m para a cultura do feijão irrigado (WUTKE et al., 2000; PIRES et al., 2001), utilizando-se da seguinte equação:

$$
\mathrm{CAD}=10\left(\theta_{\mathrm{cc}}-\theta_{\mathrm{pmp}}\right) \mathrm{P}_{\mathrm{r}}
$$

em que,

CAD - capacidade de água disponível no solo, mm;

$\theta_{\mathrm{cc}}$ - conteúdo de água do solo na capacidade de campo, $\mathrm{cm}^{3} \mathrm{~cm}^{-3}$;

$\theta_{\mathrm{pmp}}$ - conteúdo de água do solo no ponto de murcha permanente, $\mathrm{cm}^{3} \mathrm{~cm}^{-3}, \mathrm{e}$

$\mathrm{P}_{\mathrm{r}}$ - profundidade efetiva do sistema radicular, $\mathrm{cm}$.

O valor da lâmina de água aplicada em cada irrigação foi determinado pela média das quantidades de água recebidas, após a irrigação, em 12 pluviômetros distribuídos em cada parcela. Nas profundidades de 0,20 e 0,40 m, foi determinado o potencial de água no solo por meio de medições realizadas com tensiômetros instalados nas parcelas.

A capacidade de campo foi determinada utilizando-se da curva de retenção de água no solo para o potencial mátrico de $-100 \mathrm{kPa}$, ajustada pela expressão matemática desenvolvida por GENUCHTEN (1980):

$$
\theta=\theta_{r}+\frac{\left(\theta_{s}-\theta_{r}\right)}{\left[1+(|\Psi| \alpha)^{n}\right]^{m}}
$$

em que,

$\theta$ - umidade à base de volume, $\mathrm{cm}^{-3} \mathrm{~cm}^{-3}$;

$\Psi$ - potencial mátrico de água no solo, $\mathrm{cm}$;

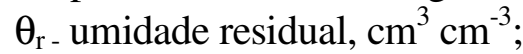

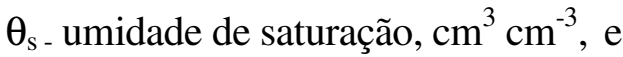

$\alpha, \mathrm{m}$ e $\mathrm{n}$ - parâmetros empíricos do modelo matemático.

A quantidade de água aplicada em cada parcela foi em função dos valores da ETc obtidos por meio de dados coletados em um tanque Classe A e do coeficiente cultural $(\mathrm{Kc})$, sendo a ETc calculada por intermédio das seguintes equações:

$$
\begin{aligned}
& \mathrm{ETo}=\mathrm{ECA} \mathrm{K}_{\mathrm{p}} \\
& \mathrm{ETc}=\mathrm{ETo} \mathrm{K}_{\mathrm{c}}
\end{aligned}
$$

em que,

ETo - evapotranspiração de referência, mm;

ECA -evaporação medida no tanque "Classe A", $\mathrm{mm} \mathrm{dia}^{-1}$;

$\mathrm{K}_{\mathrm{p}}$ - coeficiente do tanque "Classe A"(adimensional),

ETc - evapotranspiração da cultura, $\mathrm{mm} \mathrm{dia}^{-1}$, e

$\mathrm{K}_{\mathrm{c}}$ - coeficiente da cultura. 
As medições da condutância estomática da cultura foram efetuadas utilizando-se de um porômetro em estado de equilíbrio dinâmico (Steady State Porometer, LI-1600 da LICOR), com medidas diretas de condutância estomática. Tais medições foram feitas nas faces adaxial e abaxial de folhas da cultura do feijão (Phaseolus vulgaris), localizadas na parte superior da planta, expostas à radiação solar. Quatro plantas foram tomadas ao acaso por ocasião de cada medição. Em cada planta, uma folha da parte superior totalmente expandida e exposta à radiação solar foi selecionada para fazer tais medidas (RODRIGUES, 1984).

As medições foram realizadas entre $11 \mathrm{~h} \mathrm{e} 14 \mathrm{~h}$, por corresponder ao intervalo no qual se situa o pico da radiação solar na região de Jaboticabal, no período da amostragem. Essas medidas foram realizadas a partir dos 20 dias após a emergência (d.a.e), quando as plantas apresentaram área foliar adequada ao adaptador do porômetro. Foram efetuadas medições diárias, desde que o dia estivesse ensolarado, céu claro e sem nuvens, para que a condutância estomática medida expressasse o real comportamento da cultura em relação à umidade do solo.

A condutância total da folha foi obtida admitindo-se que as condutâncias abaxial e adaxial agem em série, efetuando-se o somatório da condutância das duas faces da folha.

A medida da radiação solar global foi realizada durante o período em que foi realizado o experimento com um piranômetro da marca Eppley (modelo 8.48), com compensação de temperatura, (constante de calibração de $12,8010^{-6} \mathrm{VW}^{-1} \mathrm{~m}^{-2}$ ), sendo o déficit de pressão de vapor calculado utilizando a umidade relativa e temperatura do ar durante o período em que foi realizado o experimento, no horário de 12 h 30, abrangendo o horário em que foram efetuadas as medições de condutância estomática.

\section{RESULTADOS E DISCUSSÃO}

$\mathrm{Na}$ Tabela 1, apresentam-se os estádios fenológicos da cultura com as respectivas descrições e ocorrência de cada estádio, de acordo com GEPTS \& FERNÁNDEZ (1982).

TABELA 1. Caracterização dos estádios fenológicos do feijoeiro.

\begin{tabular}{ccc}
\hline Estádio & Descrição & Ocorrência (d.a.e** \\
\hline V4 & Emissão da terceira folha trifoliada & 21 \\
R6 & Floração & 40 \\
R8 & Enchimento de grãos & 65 \\
R9 & Modificação da cor das vagens & 82 \\
\hline
\end{tabular}

* Dias após emergência

A precipitação durante o ciclo da cultura foi de $49 \mathrm{~mm}$, sendo que $35 \mathrm{~mm}$ ocorreram nos primeiros 24 dias após a emergência. A lâmina total de água via irrigação foi $191 \mathrm{~mm}$, distribuída em oito aplicações no tratamento T1, com duas aplicações no estádio V4, quatro no estádio R6 e duas no estádio R8. Para o T2, foram aplicados $187 \mathrm{~mm}$ em cinco vezes, com uma aplicação no estádio V4, três no estádio R6 e uma no estádio R8. Para o T3, foram $173 \mathrm{~mm}$ em quatro aplicações, sendo uma no estádio V4, duas no estádio R6 e uma no estádio R8, e $43 \mathrm{~mm}$ em uma aplicação para o T4 efetuada no estádio V4.

Na Figura 1, são apresentadas a radiação e o déficit de pressão de vapor nos diferentes estádios de crescimento e desenvolvimento da cultura. Observa-se que o déficit de pressão de vapor apresentou oscilações ao longo do ciclo, porém nem sempre se verificou relação da condutância estomática com o mesmo, já que o movimento de abertura e fechamento dos estômatos depende também de outros fatores, como luz, $\mathrm{CO}_{2}$, estado hídrico da folha, umidade do ambiente, temperatura e outros fatores, como idade da folha, nutrição e doenças (JONES, 1992). 


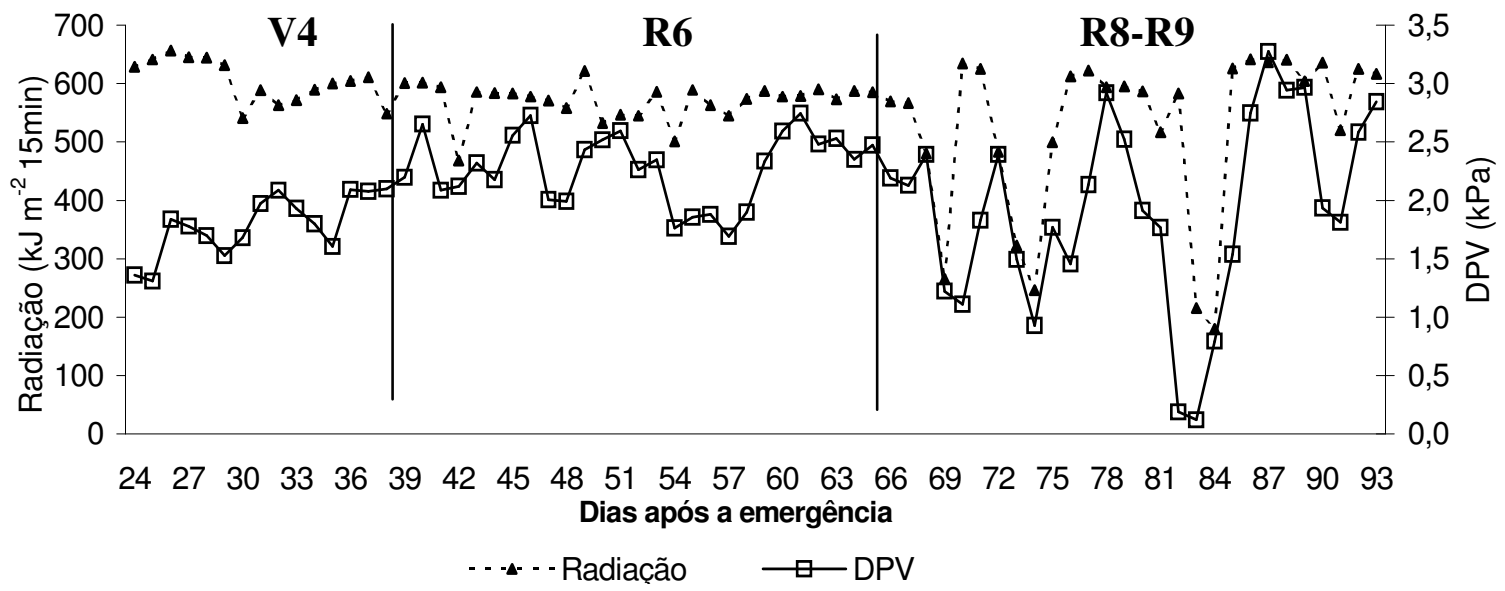

FIGURA 1. Radiação e déficit de pressão de vapor (DPV) durante os estádios de desenvolvimento da cultura do feijão, no período entre 11 e 14 h.

Na Figura 2, são apresentados a condutância estomática e o potencial de água no solo, nos diferentes estádios de crescimento e desenvolvimento, e as respectivas irrigações efetuadas e precipitações ocorridas no período em que foram realizadas as medições. Verificou-se que, no estádio V4, os valores de condutância estomática foram baixos em todos os tratamentos, observando-se pequena variação no potencial de água no solo, exceto no tratamento T4. Esse estádio apresentou valores médios de condutância estomática de 456,01; 396,85; 278,76 e 322,02 $\mathrm{mmol} \mathrm{m}^{-2} \mathrm{~s}^{-1}$ para os tratamentos $\mathrm{T} 1, \mathrm{~T} 2, \mathrm{~T} 3 \mathrm{e} \mathrm{T} 4$, respectivamente.

Nota-se que o tratamento T1, com maior freqüência de irrigação, apresentou maior valor de condutância estomática, provavelmente pela melhor condição hídrica da planta durante esse estádio. No estádio R6, houve grandes variações no potencial de água no solo entre os tratamentos devido às irrigações efetuadas em dias diferenciados, em função da CAD de cada tratamento. Esse estádio apresentou os maiores valores médios de condutância estomática de 726,64; 784,38; 678,67 e $440,85 \mathrm{mmol} \mathrm{m}^{-2} \mathrm{~s}^{-1}$ para os tratamentos T1, T2, T3 e T4, respectivamente, caracterizando maior abertura dos estômatos, favorecendo a perda de água pela folha. Essa perda é mais acentuada nos tratamentos com maior reserva hídrica no solo, como verificado por MWANAMWENGE et al. (1999), em folhas de feijão-fava.

Aos 63 D.A.E foram desativados os tensiômetros do tratamento T4, devido ao esgotamento de água no solo; as plantas, em função da menor reserva hídrica no solo que os demais tratamentos, apresentaram menores valores de condutância estomática, caracterizando o fechamento estomático e evitando a perda de água pela folha nesse período crítico ao estresse hídrico. Para os mesmos níveis de radiação (Figura 1), verificaram-se diferentes valores de condutância estomática; possivelmente, as flutuações das condições meteorológicas, como velocidade do vento, nebulosidade parcial, entre outras, afetaram a condutância estomática.

No estádio R8, as folhas das plantas do tratamento T4, submetido a menor disponibilidade de água, apresentaram condutância estomática média de $256,01 \mathrm{mmol} \mathrm{m}^{-2} \mathrm{~s}^{-1}$, destacando-se dos demais tratamentos que apresentaram valores médios de condutância de 610,$89 ; 648,74$ e $772,70 \mathrm{mmol} \mathrm{m}^{-2} \mathrm{~s}^{-1}$ para os tratamentos $\mathrm{T} 1, \mathrm{~T} 2$ e $\mathrm{T} 3$, respectivamente.

A partir dos 90 D.A.E., independentemente do potencial mátrico, o tratamento T3 apresentou os maiores valores de condutância estomática comparado aos tratamentos T1 e T2, indicando que, no final do ciclo, a condutância estomática não se relacionou diretamente com o potencial hídrico do solo medido a $40 \mathrm{~cm}$. 


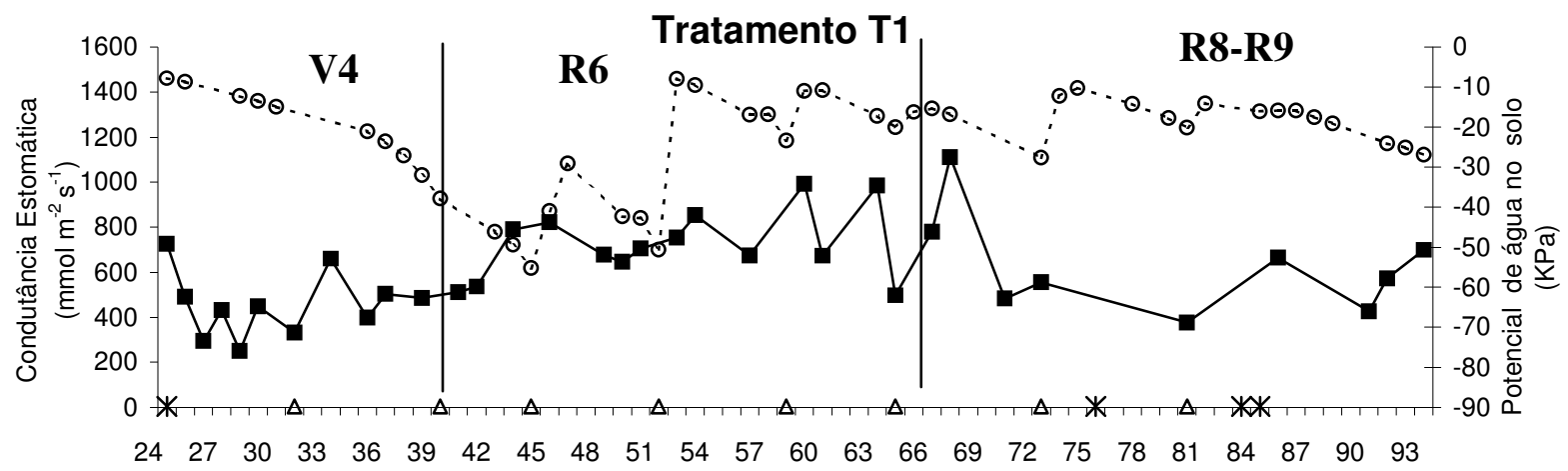

Dias após a emergência

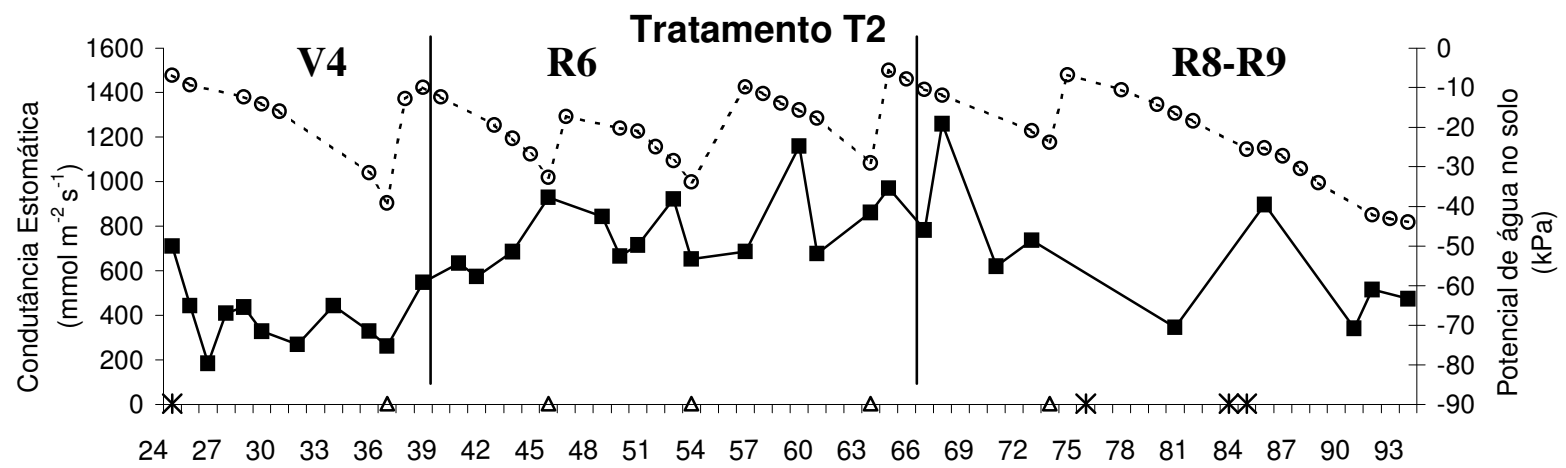

Dias após a emergência

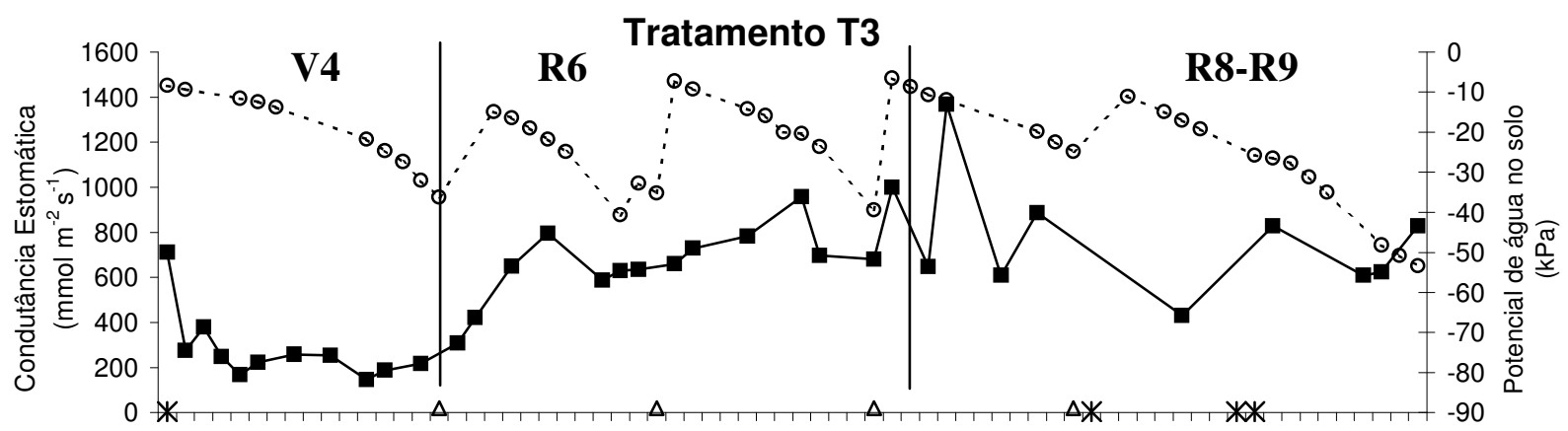

$\begin{array}{llllllllllllllllllllllll}24 & 27 & 30 & 33 & 36 & 39 & 42 & 45 & 48 & 51 & 54 & 57 & 60 & 63 & 66 & 69 & 72 & 75 & 78 & 81 & 84 & 87 & 90 & 93\end{array}$

Dias após a emergência

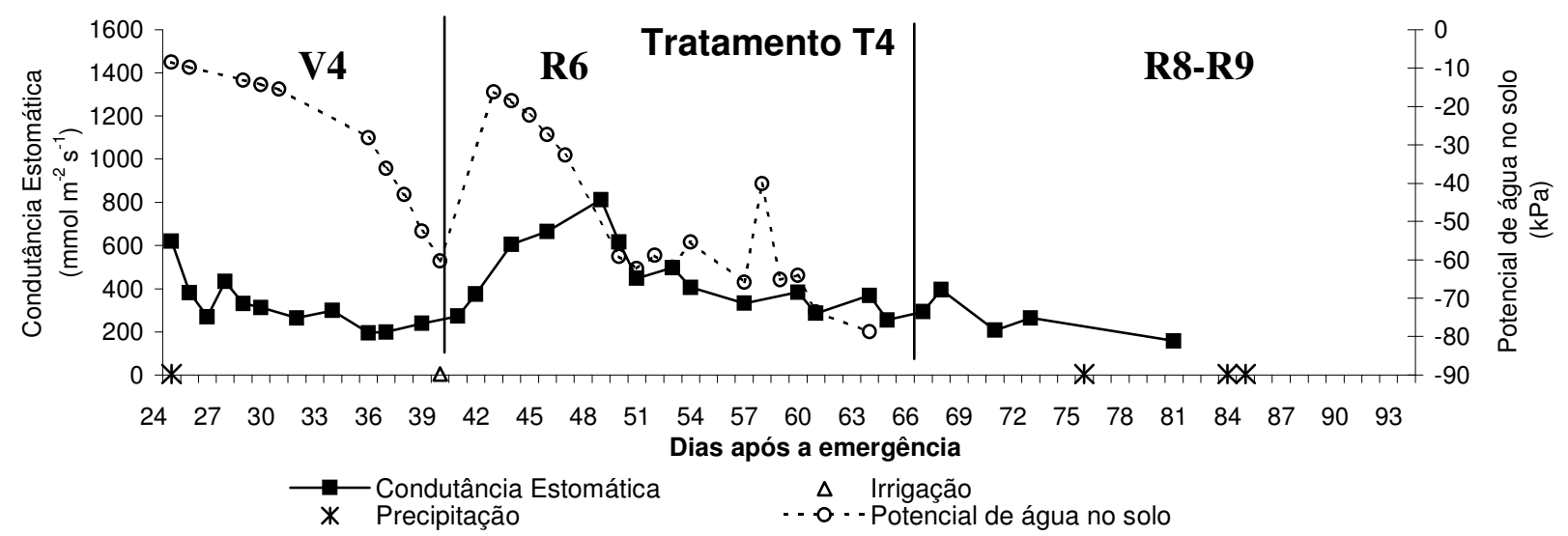

FIGURA 2. Valores de potencial de água no solo e condutância estomática para os diferentes tratamentos durante o ciclo da cultura de feijão, no período de 23 de maio a 31 de julho de 2002. 
Não foram verificadas grandes diferenças nos valores médios de condutância estomática entre o tratamento T1 e os tratamentos T2 e T3 durante o ciclo da cultura, mesmo observando-se variação no potencial de água no solo. Possivelmente, as limitações hídricas impostas a esses dois tratamentos não foram suficientes para provocar grandes variações na condutância estomática. Contudo, esse comportamento não foi verificado quando a limitação hídrica foi acentuada, como observado no tratamento T4. Isso indica que, quando o déficit de água no solo não é muito acentuado, as variações da condutância estomática obedecem à mesma tendência das plantas sem restrição hídrica. Resultados de SCHURR et al. (1992) em girassol e BERGONCI et al. (2000) com milho confirmam essa observação.

Na Tabela 2, apresentam-se os valores médios de condutância estomática, potencial de água no solo, déficit de pressão de vapor (DPV) e radiação durante os estádios de desenvolvimento da cultura. Observa-se que os maiores valores médios de condutância estomática ocorreram no estádio R6, verificando-se maior exigência hídrica da cultura nessa fase, pela maior frequiência de irrigação efetuada durante esse estádio. Nota-se, também, nesse estádio, maior déficit de pressão de vapor. Considerando que essa fase é a de maior exigência hídrica da cultura, observou-se que os tratamentos, mesmo apresentando menor potencial hídrico no solo durante esse estádio do que no estádio V4, apresentaram altos valores de condutância estomática, mantendo os estômatos abertos e favorecendo a transpiração, apesar da alta demanda atmosférica ocorrida nesse período.

Ainda no estádio R6, observa-se que o tratamento T3, com maior potencial hídrico no solo do que o T1, apresentou menor valor médio de condutância estomática do que esse. Isso provavelmente ocorreu devido ao tratamento T3 ter sido submetido à menor frequiência de irrigação do que o T1. É interessante notar que, em diversos valores pontuais, houve correspondência entre altos valores de DPV e baixos valores de condutância estomática e vice-versa, indicando que os valores médios nem sempre se mostraram adequados para as comparações entre a condutância e a umidade do ar.

TABELA 2. Valores médios de condutância estomática, potencial de água no solo, déficit de pressão de vapor (DPV) e radiação nos quatro tratamentos durante os estádios de desenvolvimento da cultura do feijão.

\begin{tabular}{|c|c|c|c|c|c|}
\hline \multirow[t]{2}{*}{ Estádio } & \multirow[t]{2}{*}{ Tratamentos } & $\begin{array}{l}\text { Condutância } \\
\text { Estomática }\end{array}$ & $\begin{array}{c}\text { Potencial de água } \\
\text { no Solo }\end{array}$ & DPV & Radiação \\
\hline & & $\mathrm{mmol} \mathrm{m}^{-2} \mathrm{~s}^{-1}$ & $\mathrm{kPa}$ & $\mathrm{kPa}$ & $\mathrm{MJ} \mathrm{m}^{-2} 15 \mathrm{~min}$ \\
\hline \multirow{4}{*}{ V4 } & $\mathrm{T} 1$ & $456,01 \pm 143,58$ & $-19,86 \pm 10,16$ & \multirow{4}{*}{$1,82 \pm 0,27$} & \multirow{4}{*}{$604,26 \pm 35,71$} \\
\hline & $\mathrm{T} 2$ & $396,85 \pm 147,21$ & $-16,45 \pm 10,41$ & & \\
\hline & $\mathrm{T} 3$ & $278,76 \pm 156,10$ & $-19,77 \pm 10,00$ & & \\
\hline & $\mathrm{T} 4$ & $322,02 \pm 122,33$ & $-28,12 \pm 18,90$ & & \\
\hline \multirow{4}{*}{ R6 } & T1 & $726,64 \pm 151,17$ & $-27,43 \pm 16,16$ & \multirow{4}{*}{$2,28 \pm 0,30$} & \multirow{4}{*}{$569,51 \pm 31,34$} \\
\hline & $\mathrm{T} 2$ & $784,38 \pm 160,31$ & $-19,41 \pm 8,39$ & & \\
\hline & $\mathrm{T} 3$ & $678,67 \pm 147,65$ & $-20,09 \pm 10,55$ & & \\
\hline & $\mathrm{T} 4$ & $440,85 \pm 165,54$ & $-50,11 \pm 20,57$ & & \\
\hline \multirow{4}{*}{ R8-R9 } & T1 & $610,89 \pm 230,31$ & $-18,34 \pm 5,20$ & \multirow{4}{*}{$1,92 \pm 0,83$} & \multirow{4}{*}{$525,10 \pm 145,44$} \\
\hline & $\mathrm{T} 2$ & $648,74 \pm 311,18$ & $-24,66 \pm 11,70$ & & \\
\hline & $\mathrm{T} 3$ & $772,70 \pm 283,90$ & $-27,50 \pm 13,30$ & & \\
\hline & $\mathrm{T} 4$ & $256,01 \pm 102,35$ & - & & \\
\hline
\end{tabular}

Durante os estádios R8 e R9, notam-se valores de condutância estomática superiores aos do estádio V4 nos tratamentos T1, T2 e T3, não se observando relação direta, nesses tratamentos, dos valores de condutância estomática com os de potencial de água no solo durante esse estádio de desenvolvimento da cultura. A ocorrência de controvérsias sobre as respostas das plantas às interações entre os diversos fatores que atuam no meio e considerando que o presente trabalho foi conduzido a 
campo, onde ocorre grande interação de fatores que atuam no comportamento estomático e a resposta a um determinado fator pode sofrer influência de outros fatores, evidencia a necessidade de mais estudos sobre esse assunto, visando a confirmar as relações entre as plantas e os diversos fatores atuantes no meio.

\section{CONCLUSÕES}

Em todos os tratamentos, foi observada redução da condutância estomática em resposta a baixos valores de potencial hídrico do solo e a altos valores de déficit de pressão de vapor e aumento da condutância estomática a altos valores de potencial hídrico do solo e baixos valores de déficit de pressão de vapor.

As folhas das plantas do tratamento T4, submetido a menor disponibilidade hídrica no solo, apresentaram menores valores médios de condutância estomática nos estádios R6 e R8 do que as dos demais tratamentos.

\section{REFERÊNCIAS}

ALLEN, R.G.; PEREIRA, L.S.; RAES, D.; SMITH, M. Crop evapotranpiration-guidelines for computing crop water requirements. Roma: FAO, 1998. 300 p. (Irrigation and Drainage, 56)

ALOISI, R.; DEMATTÊ, J.L.S. Levantamento dos solos da Faculdade de Medicina Veterinária e Agronomia de Jaboticabal. Científica, Jaboticabal, v.2, n.2, p.123-36, 1974.

ANDRIOLI, I.; CENTURION, J.F. Levantamento detalhado dos solos da Faculdade de Ciências Agrárias e Veterinárias de Jaboticabal. In: CONGRESSO BRASILEIRO DE CIÊNCIA DO SOLO, 27., 1999, Brasília. Anais... Brasília: Sociedade Brasileira de Ciência do Solo, 1999. p.4-9.

BERGONCI, J.I.; BERGAMASCHI, H.; ROSA, L.M.G.; SANTOS, A.O. Condutância foliar como um indicador de déficit hídrico em milho. Revista Brasileira de Agrometeorologia, Santa Maria, v.8, n.1, p.27-34, 2000.

EMBRAPA. Sistema brasileiro de classificação de solos. Rio de Janeiro, 1999. 412 p.

GENUCHTEN, M. van. A closed-form equation for predicting the hydraulic conductivity of unsaturated soils. Soil Science Society America Journal, Madison, v.41, p.892-8, 1980.

GEPTS, P.; FERNÁNDEZ, F. Etapas de desarrollo de la planta de frijol comum (Phaseolus vulgaris $L$.). Cali: CIAT, 1982. 10 p. Mimeografado

GHOLZ,. H.L.; EWEL, K.C.; TESKEY, R.O. Water and forest productivity. Forest Ecological Management, Amsterdam, v.30, n.1, p.1-18, 1990.

JONES, H.G. Plants and microclimate. $2^{\text {nd }}$ ed. Cambridge: University Press, 1992. 428 p.

Mc DERMIT, D.K. Sources of error in the estimation of stomatal conductance and transpiration from porometer data. HortScience, Alexandria, v.25, n.12, p.1538-48, 1990.

MWANAMWENGE, J.; LOSS, S.P.; SIDDIQUE, K.H.M.; COCKS, P.S. Effect of water stress during floral initiation, flowering and podding on the growth and yield of faba bean (Vicia faba L). European Journal of Agronomy, Montrouge, v.11, n.1, p.1-11, 1999.

PIRES, R.C.M.; SAKAI, E.; ARRUDA, F.B.; FOLEGATTI, M.V. Necessidades hídricas das culturas e manejo de irrigação. In: MIRANDA, J.H.; PIRES, R.C.M. Irrigação. Piracicaba: SBEA, 2001. v.1, p.121-94 (Série Engenharia Agrícola).

RODRIGUES, T.J.D. Drought resistance mechanisms among peanut genotypes, 1984. 104 f.

Dissertation (PhD) - University of Florida, Gainesville, 1984. 
ROSA, L.M.; DILLENBURG, L.R.; FORSETH, I.N. Responses of soybean leaf angle, photosynthesis and stomatal conductance to leaf and soil water potential. Annals of Botany, London, v.67, n.1, p.51-8, 1991.

SCHURR, L.; GOLLAN, T.; SCHULZE, E. D. Stomatal response to drying soil relation to changes in the xylem sap concentration of Helianthus annuus. I. Stomatal sensitivity to absicisic acid imported from the xylem sap. Plant Cell and Environment, Oxford, v.15, n.4, p.561-7, 1992.

SHALHEVET, J. Plants under salt and water stress. In: FOWDEN, L.; MANSFIELD, T.;

STODDART, J. Plant adaptation to environmental stress. London: Chapman \& Hall, 1983. cap 7, p.133-54.

WUTKE, E.B.; ARRUDA, F.B.; FANCELLI, A.L.; PEREIRA, J.C.V.N.A.; SAKAI, E.; FUJIWARA, M.; AMBROSANO, G.M.B. Propriedades do solo e sistema radicular do feijoeiro irrigado em rotação de culturas. Revista Brasileira de Ciência do Solo, Viçosa - MG, v.24, n.3, p.621-33, 2000. 